\title{
Efektifitas Insektisida Berbahan Aktif Klorantraniliprol terhadap Larva Spodoptera frugiperda (JE Smith)
}

\author{
Effectivity of Chlorantraniliprole Insecticide against the larva of Spodoptera frugiperda (JE \\ Smith) \\ Willing Bagariang ${ }^{1)}$, Enie Tauruslina ${ }^{1)^{*}}$, Umi Kulsum ${ }^{1)}$, Tri Murniningtyas $\mathrm{PL}^{1)}$, Hadi \\ Suyanto $^{1)}$, Surono ${ }^{1}$, Nanar A Cahyana ${ }^{1}$, Didah Mahmuda ${ }^{1)}$ \\ 1) Balai Besar Peramalan Organisme Pengganggu Tumbuhan, Kementerian Pertanian \\ Jl. Raya Kaliasin Tromol Pos 1, Jatisari, Kabupaten Karawang \\ E-mail: etauruslina@yahoo.com \\ Diterima: 16 Mei 2020 Disetujui: 25 Juni 2020 Dipublikasi: 30 Juni 2020
}

\begin{abstract}
Fall armyworm or Spodoptera frugiperda (J.E Smith) is a significant economic pest of maize. S. frugiperda is reported for the first time to attack and damage the corn in Indonesia since 2019. The study was aimed to find the effectivity of chlorantraniliprole to control the larvae of $S$. frugiperda on maize. The study was divided into two steps, in the laboratory and the field. The laboratory treatment was application of chlorantraniliprole 2 $\mathrm{cc} / \mathrm{l}$, Metarhizium anisopliae $\left(10^{8}\right.$ conidia $\left./ \mathrm{ml}\right)$, and Beauveria bassiana $\left(10^{8}\right.$ conidia/ml) that applied onto the leaf, larvae, and leaf + larvae with five replications for each treatment. The field test used three treatments i.e., chlorantraniliprole field, farmer field, and control with three replications for each treatment. The research showed that chlorantraniliprole at a dose of $2 \mathrm{cc} / \mathrm{l}$ had the highest mortality of $S$. frugiperda with $100 \%$ mortality on average during five days after application. However, the application of $M$. anisopliae and $B$. bassiana did not affect the mortality of $S$. frugiperda for 3 days after application. There was no difference in mortality when chlorantraniliprole applied onto leaf, larvae and leaf + larvae. Application of chlorantraniliprole in the field at a dose of $2 \mathrm{cc} / \mathrm{l}$ at 1,3 , and 5 weeks after planting was effective to control S. frugiperda on maize.
\end{abstract}

Keywords: Chlorantraniliprole, entomopatogenic fungi, fall armywarm

\section{PENDAHULUAN}

Ulat grayak jagung atau fall armyworm (Spodoptera frugiperda, Lepidoptera: Noctuidae) merupakan hama tanaman jagung yang baru masuk ke Indonesia. Hama ini awalnya berasal dari bagian tropik dan subtropik benua Amerika dan pada beberapa tahun terakhir telah menyebar ke berbagai wilayah di dunia seperti Afrika Barat dan Afrika Tengah tahun 2016 (Goergen et al., 2016) serta beberapa negara di Asia tahun 2018 (CABI, 2020). Pada tahun 2019, S. frugipreda dilaporkan pertama kali menyerang tanaman jagung di Lampung, Indonesia (Trisyono et al., 2019) dan Jawa Barat (Maharani et al., 2019). Balai Besar Peramalan Organisme Penggangu Tumbuhan (BBPOPT) juga telah menemukan hama ini pada tanaman jagung di 29 provinsi sampai bulan April 2020 (BBPOPT 2020, tidak dipublikasikan). Penyebaran $S$. frugiperda yang begitu cepat melintasi 
beberapa negara atau wilayah ini disebabkan oleh beberapa faktor di antaranya kemampuan adaptasi yang baik pada lingkungan baru, kemampuan terbang yang jauh mencapai ratusan kilometer dan kemungkinan terbawa alat transportasi (Westbrook et al., 2016; Faulkner et al., 2017).

Serangga S. frugiperda dapat menyerang seluruh stadia tanaman jagung mulai dari fase vegetatif sampai fase generatif (Prasanna et al., 2018) dan tingkat kerusakan yang tertinggi banyak ditemukan pada fase vegetatif (Trisyono et al., 2019). Siklus hidup berkisar antara 32-46 hari dengan stadia telur 2-3 hari, larva 14-19 hari dan pupa 9-12 hari (Sharanabasappa et al., 2018). Kerusakan yang ditimbulkan pada daun dan tongkol jagung mengakibatkan terjadinya kehilangan hasil secara signifikan. Di Honduras, tingkat kehilangan hasil mencapai $40 \%$ (Wyckhuys dan O'Neil, 2006), di Argentina sebesar 72\% (Murúa et al., 2006) dan di Afrika berkisar antara 21-53\% (Day et al., 2017). Di Lampung, serangan S. frugiperda dilaporkan telah menyebabkan kerusakan berat pada tanaman jagung berumur 2 minggu dengan persentase serangan mencapai $100 \%$ (Trisyono et al., 2019). Selain tanaman jagung, $S$. frugiperda juga memiliki 353 tanaman inang dari 76 famili tanaman (Montezano et al., 2018).

Invasi S. frugiperda di Indonesia dapat menjadi ancaman terhadap produksi jagung, sehingga perlu dilakukan studi yang komprehensif. Studi saat ini masih dalam tahap awal, dimana keberadaan $S$. frugiperda baru dilaporkan pada tahun 2019 (Maharani et al., 2019; Trisyono et al., 2019). Di lapangan, petani jagung di Indonesia lebih banyak menggunakan teknik pengendalian secara kimiawi. Beberapa insektisida potensial untuk pengendalian seperti spinetoram, spinosad, lamda sihalotrin, dan klorantraniliprol dengan tingkat efektifitas mencapai $90 \%$ pada 72 jam setelah aplikasi (Sisay et al., 2019). Dari kelompok cendawan entomopatogen, Beuveria bassiana, Metarhizium anisopliae dan Metarhiziun rileyi dilaporkan berpotensi menjadi agen pengendali hayati (Wright et al., 2010; Prasanna et al., 2018).

Penelitian tentang efektifitas klorantraniliprol yang merupakan golongan baru insektisida selektif (Anthranilic diamides) terhadap $S$. frugiperda pada tanaman jagung masih belum dilaporkan di Indonesia. Oleh karena itu, Balai Besar Peramalan Organisme Pengganggu Tumbuhan sebagai salah institusi yang memberikan rujukan pengendalian organisme pengganggu tumbuhan (OPT) melakukan penelitian ini dengan tujuan untuk mengetahui tingkat efektifitas insektisida klorantraniliprol dalam menekan populasi $S$. fugiperda, mengetahui sasaran aplikasi yang tepat, dan mengetahui intensitas serangan S. frugiperda setelah aplikasi dan pengaruhnya terhadap hasil panen.

\section{METODOLOGI}

Penelitian dilakukan di laboratorium dan lapangan. Penelitian laboratorium dilakukan di Laboratorium Pengamatan Hama dan Penyakit Trimurjo, Lampung pada bulan Juli 2019 dan Laboratorium Balai Besar Peramalan Organisme Pengganggu Tumbuhan pada bulan September 2019. Penelitian laboratorium ini ditujukan untuk mengetahui efektifitas insektisida klorantraniliprol dalam menekan populasi S. fugiperda, dan untuk mengetahui sasaran aplikasi yang tepat. Penelitian lapangan dilakukan di Desa Pabedilan Lor, Kecamatan Pabedilan, Kabupaten Cirebon pada bulan September sampai November 2019. Penelitian lapangan ditujukan untuk mengetahui intensitas serangan $S$. frugiperda setelah aplikasi klorantraniliprol dan pengaruhnya terhadap hasil panen. 
Bagariang et al., Efektifitas Insektisida Berbahan Aktif Klorantraniliprol

\section{Efektifitas klorantraniliprol}

Penelitian ini merupakan penelitian pendahuluan untuk mengetahui efektifitas klorantraniliprol, B. bassiana dan $M$. anisopliae terhadap mortalitas larva S. frugiperda. Perlakuan yang paling efektif akan dilakukan uji lanjut sampai pada tingkat lapang. Uji pendahuluan menggunakan Rancangan Acak Lengkap Faktorial 2 Faktor (4x2). Faktor pertama adalah jenis bahan pengendali (klorantraniliprol-2 cc/l, M. anisopliae $-10^{8}$ konidia/ml, B. bassiana- $10^{8}$ konidia/ml dan kontrol (tanpa perlakuan)). Dosis yang digunakan untuk klorantraniliprol adalah sesuai dosis anjuran, sedangkan untuk $M$. anisopliae dan $B$. bassiana menggunakan standar kerapatan konidia agens pengendali hayati berdasarkan SNI 8027 Tahun 2014 yaitu $\geq 10^{6}$ konidia/ml. Faktor kedua adalah perbedaan instar (instar 2-3, dan instar 4-6). Serangga uji yang digunakan sebanyak 10 larva per perlakuan.
Isolat $B$. bassiana dan $M$. anisopliae berasal dari Laboratorium Agens Hayati Balai Besar Peramalan Organisme Pengganggu Tumbuhan. Larva S. frugiperda uji adalah populasi lapangan yang berasal dari tanaman jagung terserang di Kecamatan Pekalongan, Kabupaten Lampung Timur, dikoleksi satu hari sebelum pengujian. Larva hasil koleksi dimasukkan ke dalam kotak plastik dan diberi pakan berupa daun jagung muda.

Aplikasi bahan pengendali dilakukan menggunakan handsprayer ukuran 1 liter dan disemprotkan langsung ke larva serta daun jagung. Larva yang telah diaplikasi dimasukkan ke dalam kotak plastik ukuran $15 \times 7 \mathrm{~cm}$ dengan penutup yang diberi kain kassa dan diletakkan di laboratorium pada suhu ruang $\left( \pm 28^{\circ} \mathrm{C}\right)$. Pengamatan mortalitas larva dilakukan selama 3 hari setelah aplikasi, dan dihitung menurut Natawigena (1993) dengan rumus:

\section{Mortalitas $=$ Jumlah larva yang mati $\times 100 \%$ Jumlah seluruh larva uji}

\section{Efektifitas beberapa sasaran aplikasi klorantraniliprol}

Penelitian ini menggunakan 4 perlakuan dan 3 ulangan. Perlakuannya berupa aplikasi klorantraniliprol pada larva, pada daun serta pada larva+daun, dan kontrol. Stadia larva yang digunakan adalah larva instar 3 sebanyak 10 ekor per perlakuan, sedangkan dosis klorantraniliprol adalah $2 \mathrm{cc} / \mathrm{l}$. Klorantraniliprol diaplikasikan menggunakan handsprayer ukuran 1 liter. Pengamatan mortalitas larva dilakukan pada $1,2,3$ dan 5 hari setelah aplikasi, dan dihitung berdasar rumus Natawigena (1993):

\section{Mortalitas $=\underline{\text { Jumlah larva yang mati }} \times 100 \%$ Jumlah seluruh larva uji}

Intensitas serangan S. frugiperda setelah diaplikasi dengan klorantraniliprol di lapangan

Penelitian dilaksanakan pada lahan petani jagung di Desa Pabedilan Lor, Kecamatan Pabedilan, Cirebon menggunakan Rancangan Acak Kelompok dengan 3 perlakuan (lahan dengan aplikasi klorantraniliprol, lahan petani, dan kontrol), masing-masing dalam 3 ulangan. Petak perlakuan masing-masing beruku- ran $8 \times 10 \mathrm{~m}$ dengan jarak tanam $75 \mathrm{~cm} \mathrm{x}$ $20 \mathrm{~cm}$. Varietas jagung yang digunakan pada seluruh perlakuan adalah varietas Exsotic Pertiwi dengan sistem budidaya jagung yang umum dilakukan oleh petani. Aplikasi pestisida yang dilakukan oleh petani dengan melakukan pencampuran beberapa bahan aktif pestisida dengan frekuensi aplikasi sebanyak 2 kali yaitu pada umur tanaman 30 dan 55 hari setelah tanam. Lahan dengan perlakuan 
klorantraniliprol menggunakan dosis $2 \mathrm{cc} / \mathrm{l}$ (volume semprot 400-600 l/ha) yang diaplikasi sebanyak 3 kali yaitu pada umur tanaman 1, 3 dan 5 MST. Aplikasi dilakukan pada sore hari menggunakan knapsack sprayer ukuran 15 liter.

Tingkat kerusakan daun jagung di lapangan ditentukan menggunakan skala Davis (Skor 0-9) dan kemudian dikonversikan ke dalam rumus intensiitas serangan (IS). Pengamatan kerusakan dilakukan dari daun yang belum terbuka sampai daun ke3. Deskripsi skala Davis berdasarkan kerusakan daun adalah sebagai berikut:

Skor 0 Tidak terlihat kerusakan pada daun Skor 1 Kerusakan sebesar lubang jarum

Skor 2 Kerusakan sebesar lubang jarum dan lubang kecil melingkar pada daun

Skor 3 Terlihat kerusakan sebesar lubang jarum, lesi kecil melingkar dan sedikit lesi kecil memanjang (bentuk persegi panjang) dengan panjang mencapai $1,3 \mathrm{~cm}$ pada gulungan dan helaian daun.

Skor 4 Beberapa lesi kecil dan sedang memanjang dengan panjang 1,3 $2,5 \mathrm{~cm}$ nampak pada gulungan dan helaian daun

Skor 5 Beberapa lesi berukuran besar yang memanjang dengan ukuran lebih dari $2,5 \mathrm{~cm}$ terlihat pada gulungan dan helaian daun dan /atau beberapa lubang ber-bentuk seragam - tidak beraturan berukuran kecil hingga menengah (membran bagian bawah termakan) terlihat pada gulungan atau helaian daun.

Skor 6 Beberapa lesi memanjang berukuran besar terlihat pada beberapa gulungan dan/atau helaian daun dan/atau beberapa lubang besar dengan bentuk seragam sampai tidak beraturan terlihat pada gulungan dan helaian daun.
Skor 7 Banyak lesi memanjang dari semua ukuran terlihat pada beberapa helaian dan gulungan daun ditambah beberapa lubang besar dengan ukuran seragam - tidak beraturan yang nampak pada gulungan dan helaian daun.

Skor 8 Banyak lesi memanjang dari semua ukuran terdapat pada sebagian besar gulungan dan helaian daun ditambah banyak lubang seragam tidak beraturan, berukuran sedang hingga besar terlihat pada gulungan dan helaian daun.

Skor 9 Gulungan dan helaian daun hampir hancur total

Intensitas serangan (IS) $S$. frugiperda diperoleh dengan menggunakan rumus:

IS $(\%)=\frac{\sum_{i=0}^{n}(n i x v i)}{N \times Z}$

IS = Intensitas serangan ulat grayak $S$. frugiperda (\%)

ni = Jumlah tanaman dengan skala kerusakan vi

vi = Nilai skala kerusakan berdasarkan skala Davis

$\mathrm{N}=$ Jumlah tanaman yang diamati

$\mathrm{Z}=$ Nilai skala kerusakan tertinggi

\section{Bobot tongkol jagung (g)}

Jumlah tongkol yang digunakan sebagai sampel adalah sebanyak 150 tongkol, merupakan bobot tongkol jagung pada saat panen umur 70 hari setelah tanam. Penimbangan bobot tongkol dilakukan di lahan jagung dengan menggunakan timbangan digital DLE-75 Hanging Scale.

\section{Analisis data}

Mortalitas larva S. frugiperda, intensitas serangan, dan hasil panen jagung dianalisis dengan menggunakan software Minittab 17.

\section{HASIL}


Bagariang et al., Efektifitas Insektisida Berbahan Aktif Klorantraniliprol

Mortalitas S. frugiperda pada uji efektifitas klorantraniliprol

Pada uji pendahuluan ini, klorantraniprol mampu mematikan $20 \%$ larva $S$. frugiperda satu hari setelah aplikasi. Mortalitas tersebut mencapai $90 \%$ pada

Tabel 1. Mortalitas larva S. frugiperda setelah diaplikasi dengan klorantraniliprol, $B$. bassiana, dan M. anisopliae di laboratorium

\begin{tabular}{lcccccc}
\hline \multirow{2}{*}{ Perlakuan } & \multicolumn{3}{c}{ Larva instar $2-3(\%)$} & \multicolumn{3}{c}{ Larva instar 4-6 (\%) } \\
\cline { 2 - 7 } & 1 hsa & 2 hsa & 3 has & 1 hsa & 2 hsa & 3 has \\
\hline Klorantraniprol $(2 \mathrm{cc} / \mathrm{l})$ & 20 & 70 & 90 & 20 & 50 & 90 \\
Beauveria bassiana $\left(10^{8}\right.$ konidia/ml) & 0 & 0 & 0 & 0 & 0 & 0 \\
Metarhizium anisopliae $\left(10^{8}\right.$ & 0 & 0 & 0 & 0 & 0 & 0 \\
konidia/ml) & 0 & 0 & 0 & 0 & 0 & 0 \\
Kontrol & & & & &
\end{tabular}

hsa=hari setelah aplikasi

Pengaruh sasaran aplikasi klorantraniliprol

Aplikasi klorantraniliprol pada larva dan daun dapat mematikan $20 \%$ larva uji satu hari setelah aplikasi, kemampuan mematikannya lebih cepat dibandingkan aplikasi pada daun dan larva saja. Namun hari ke tiga, baik pada instar 2-3 maupun instar 4-6. Sementara itu, tidak ada kematian larva ketika diaplikasi dengan $B$. bassiana dan $M$. anisopliae (0 \%) selama 3 hari pengamatan (Tabel 1 ). pada hari berikutnya mulai terlihat, tidak ada perbedaan mortalitas antar ke tiga perlakuan. Pada hari ke 5 setelah aplikasi terlihat bahwa aplikasi insektisida klorantraniliprol dengan berbagai sasaran aplikasi dapat mematikan $100 \%$ larva uji (Tabel 2 dan Gambar 1).

Tabel 2. Mortalitas larva S. frugiperda berdasarkan sasaran aplikasi klorantraniliprol di laboratorium

\begin{tabular}{|c|c|c|c|c|c|c|}
\hline \multirow{2}{*}{ Perlakuan } & \multicolumn{6}{|c|}{ Mortalitas larva (\%) } \\
\hline & $1 \mathrm{hsa}$ & 2 hsa & & 3 hsa & $5 \mathrm{hsa}$ & \\
\hline Aplikasi pada larva & $6,7 \mathrm{~b}$ & 53,3 & a & $76,7 \mathrm{~b}$ & 100,0 & a \\
\hline Aplikasi pada daun & $3,3 \mathrm{~b}$ & 43,3 & a & 93,3 a & 100,0 & a \\
\hline Aplikasi pada larva+daun & 20,0 a & 56,7 & a & $80,0 \mathrm{~b}$ & 100,0 & a \\
\hline Kontrol & $0,0 \mathrm{~b}$ & 0,0 & $b$ & $0,0 \mathrm{c}$ & 0,0 & $b$ \\
\hline
\end{tabular}

*Nilai mortalitas larva yang diikuti oleh huruf yang berbeda pada kolom yang sama menunjukkan perbedaan yang nyata pada taraf $5 \%$ atau $\mathrm{P}<0.05$ berdasarkan uji LSD

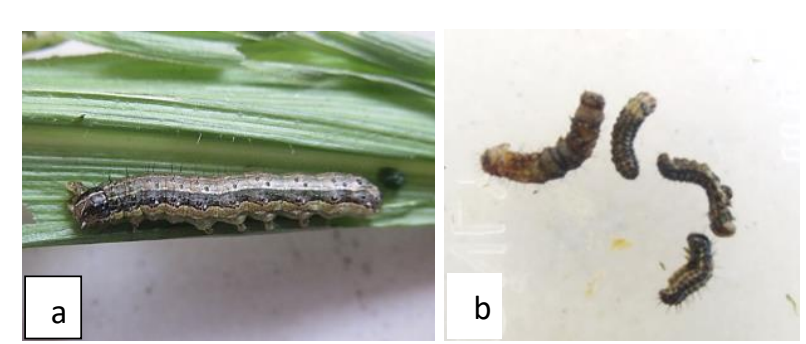

Gambar 1. Larva S. frugiperda pada pengamatan hari ke lima setelah aplikasi: a. larva sehat pada kontrol, b. Larva mati pada perlakuan aplikasi daun dan larva

Intensitas serangan setelah diaplikasi dengan klorantraniliprol di lapangan

Secara umum, intensitas serangan S. frugiperda sangat rendah di awal tanam dan meningkat hingga mencapai titik tertinggi pada saat umur tanaman 4-5 MST dan kemudian intensitas serangan $S$. frugiperda mengalami penurunan hingga 
Bagariang et al., Efektifitas Insektisida Berbahan Aktif Klorantraniliprol

umur 7 MST. Intensitas serangan $S$. frugiperda pada petak perlakuan kloranperlakuan kontrol maupun petani traniliprol lebih rendah dibandingkan

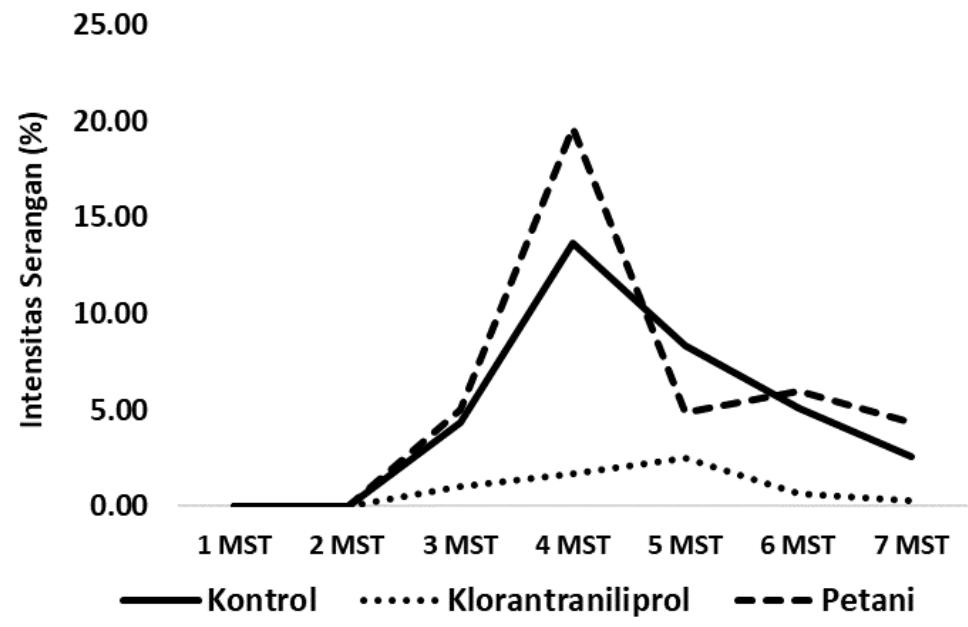

Gambar 2. Perkembangan intensitas serangan larva Spodoptera frugiperda pada tanaman jagung pada umur 1-7 MST

\section{Hasil panen}

Bobot tongkol jagung di lapangan yang diaplikasi dengan klorantraniliprol lebih tinggi dibandingkan bobot tongkol pada lahan petani dan kontrol (Tabel 3).

Tabel 3. Bobot tongkol jagung pada uji lapang setelah diaplikasi dengan klorantraniliprol (2 cc/l) pada 1, 3, dan5 MST

\begin{tabular}{|c|c|c|c|c|c|}
\hline \multirow{2}{*}{$\begin{array}{l}\text { Perlakuan } \\
\text { Klorantraniliprol }\end{array}$} & \multirow{2}{*}{$\begin{array}{c}\text { Jumlah sampel } \\
150\end{array}$} & \multicolumn{4}{|c|}{$\begin{array}{c}\text { Bobot tongkol (gram)* } \\
\text { Rataan } \pm S D\end{array}$} \\
\hline & & 0,631 & \pm & 0.075 & $\mathrm{a}$ \\
\hline Petani & 150 & 0,566 & \pm & 0.075 & b \\
\hline Kontrol & 150 & 0,471 & \pm & 0.045 & c \\
\hline
\end{tabular}

*Nilai bobot tongkol yang diikuti oleh huruf yang berbeda pada kolom yang sama menunjukkan perbedaan yang nyata pada taraf $5 \%$ atau $\mathrm{P}<0.05$ berdasarkan uji LSD

\section{PEMBAHASAN}

Berdasarkan hasil penelitian diketahui bahwa klorantraniprol mampu mematikan 90\% larva S. frugiperda pada hari ke tiga setelah aplikasi, baik pada instar 23 maupun instar 4-6 (Tabel 1). Aplikasi klorantraniprol pada daun, larva atau pada larva+daun mampu mematikan $100 \%$ larva uji setelah 5 hari aplikasi, namun aplikasi pada larva+daun mematikan larva lebih cepat dibandingkan lainnya pada 1 hari setelah aplikasi (Tabel 2).

Klorantraniliprol merupakan insektisida selektif dari grup anthranilic diamides yang tidak berbahaya bagi serangga bermanfaat seperti parasitoid, predator maupun pollinator (Dinter et al., 2008; Brugger et al., 2010). Klorantraniliprol bekerja dengan mengaktivasi ryanodine reseptor (RyR) sehingga menyebabkan terjadinya pelepasan kalsium dari sarkoplasma retikulum pada serangga yang mengakibatkan terjadinya pergerakan otot yang tidak beraturan, kelumpuhan dan diakhiri dengan kematian. Klorantraniliprol efektif mengendalikan Diptera dan Lepidoptera tertentu yang dapat bekerja sebagai racun kontak dan racun perut (Brugger et al., 2010; Liu et al., 2017), sehingga dapat diaplikasikan 
langsung pada daun, atau pada larva atau pada keduanya.

Intensitas serangan S. frugiperda pada lahan yang diaplikasi dengan klorantraniliprol lebih rendah dibandingkan lahan petani dan kontrol (Gambar 2), dan memiliki bobot tongkol jagung yang lebih tinggi (Tabel 3). Hal ini diduga karena tanaman jagung diaplikasi dengan klorantraniliprol pada 1, 3 dan 5 MST (fase vegetatif) sementara lahan petani diaplikasi dengan pestisida lain pada 30 dan 55 HST. Fase vegetatif adalah fase penting untuk pengendalian karena larva masih berada pada instar awal. Larva instar 5 atau 6 dapat menyebabkan kerusakan daun yang berat dan sulit dikendalikan karena pada umumnya akan masuk dalam gulungan daun, sehingga efektifitas pengendalian menjadi sangat rendah. Trisyono et al. (2019) menyatakan, tingkat serangan $S$. frugiperda lebih tinggi pada tanaman jagung muda. Evans dan Stansly (1990) menyatakan bahwa serangan $S$. frugiperda pada awal fase vegetatif menyebabkan kehilangan hasil yang lebih besar sehingga ambang kendali $S$. frugiperda ditetapkan berdasarkan intensitas serangan dan umur tanaman. Oleh sebab itu, pengendalian yang dilakukan pada fase awal dapat menurunkan intensitas serangan dan mempengaruhi hasil panen.

Cendawan entomopatogen merupakan agens pengendali hayati yang memiliki spektrum yang luas dalam mengendalikan berbagai hama sasaran (Prasanna et al., 2018). Pada penelitian ini, B. bassiana dan $M$. anisopliae belum menunjukkan keefektifan dalam Mengendalikan populasi larva $S$. frugiperda sampai 3 hari setelah aplikasi. Keberhasilan cendawan entomopatogen dalam mengendalikan hama sasaran sangat tergantung pada keragaman jenis isolat, kerapatan konidia, kualitas media tumbuh, jenis hama sasaran, stadia hama, waktu aplikasi, frekuensi aplikasi, dan faktor lingkungan meliputi sinar ultra violet, curah hujan, dan kelembaban (Widayat dan Rayati, 1993; Sudarmadji dan Gunawan, 1994; Suprapto dan Suroso, 1999; Junianto, 2000). Pada penelitian lain, $B$. bassiana yang diaplikasikan pada ulat grayak $S$. litura efektif pada 7 hari setelah aplikasi dengan kerapatan konidia $10^{10}$ konidia/ml dan mortalitas 82,5\% (Rosmiati et al., 2019). B. bassiana dan $M$. anisopliae juga dilaporkan efektif untuk mengendalikan Plutella xylostella, Ostrinia nubinalis, Spodoptera exigua, dan Helicoverpa armigera (Wright et al., 2010; Ozdemir et al., 2019).

\section{KESIMPULAN}

Insektisida berbahan aktif klorantraniliprol dosis $2 \mathrm{cc} / \mathrm{l}$ mampu menekan populasi larva $S$. frugiperda dengan mortalitas sebesar $100 \%$ pada 5 hari setelah aplikasi. Intensitas serangan di lapangan menurun setelah diaplikasi dengan klorantraniliprol, dan bobot tongkol lebih tinggi dari yang lainnya.

\section{UCAPAN TERIMA KASIH}

Penulis mengucapkan terima kasih kepada Guntur, SP sebagai Kepala Laboratorium Pengamatan Hama dan Penyakit Trimurjo, Lampung Timur dan Tria Wibawa, SP sebagai POPT Kecamatan Pabedilan, Cirebon yang telah memberikan kontribusi dalam pelaksanaan penelitian ini.

\section{DAFTAR PUSTAKA}

Brugger K, P Cole, I Newman, N Parker, B Scholz, P Suvagia, G Walker dan T Hammond. 2010. Selectivity of chlorantraniliprole to parasitoid wasps. Pest Management Science 2010(66): 1075-1081.

CABI. 2020. Spodoptera frugiperda (Fall Armyworm). https://www.cabi.org- 
Bagariang et al., Efektifitas Insektisida Berbahan Aktif Klorantraniliprol

/ISC/fallarmyworm. Diakses pada tanggal 15 Mei 2020.

Day R, P Abraham, M Bateman, T Beale, V Clottey, M Cock, Y Colmenarez, N Corniani, R Early, J Godwin, J Gomez, P Moreno, S Murphy, B OppongMensah, N Phiri, C Pratt, G Richards, S Silvestri dan A Witt. 2017. Fall armyworm: impacts and implications for Africa. Outlooks Pest management 28: 192-201.

Dinter $A, K$ Brugger, $N$ Frost dan $M$ Woodward. 2008. Chlorantraniliprole (Rynaxypyr): A novel DuPont $^{\mathrm{TM}}$ insecticide with low toxicity and low risk for honey bees (Apis mellifera) and bumble bees (Bombus terrestris) providing excellent tools for uses in integrated pest management 10th International Symposium of the ICP-Bee Protection Group.

Evans DC dan PA Stansly. 1990. Weekly economic injury levels for fall armyworm (Lepidoptera: Noctuidae) infestation in lowland Equador. Journal of Economic Entomology 8(6): 2452-2454.

Faulkner K, B Hurley, M Robertson, W Rouget dan J Wilson. 2017. Te balance of trade in alien species between South Africa and the rest of Africa. Bothalia-African Biodiversity and Conservation 47: 1-16.

Goergen G, P Kumar, S Sangkung, A Togola dan M Tamo. 2016. First report of outbreaks of the fall armyworm Spodoptera frugiperda (JE Smith) (Lepidoptera, Noctuidae), a new alien invasive pest in West and Central Africa. PLoS ONE 11(10): e0165632.

Junianto YD. 2000. Penggunaan Beauveria bassiana untuk pengendalian hama tanaman kopi dan kakao. Workshop Nasional Pengendalian Hayati OPT
Tanaman Perkebunan. Cipayung, 1517 Februari 2000.

Liu Y, Y Gao, G Liang dan Y Lu. 2017. Chlorantraniliprole as a candidate pesticide used in combination with the attracticides for lepidopteran moths. PLoS ONE 12(6): e0180255.

Maharani Y, V Dewi, L Puspasari, L Rizkie, Y Hidayat dan D Dono. 2019. Cases of fall army worm Spodoptera frugiperda J. E. Smith (Lepidoptera: Noctuidae) attack on maize in Bandung, Garut and Sumedang District, West Java. Jurnal Cropsaver 2(1): 38-46.

Montezano D, A Specht, D Sosa-Gomez, V Roque-Specht, J Sousa-Silva, S PaulaMoraes, J Peterson dan $\mathrm{T}$ Hunt. 2018. Host plants of Spodoptera frugiperda (Lepidoptera: Noctuidae) in the Americas. African Entomology 26(2): 286-300.

Murúa G, J Molina-Ochoa dan C Coviella. 2006. Population dynamics of the fall armyworm, Spodoptera frugiperda (Lepidoptera: Noctuidae) and its parasitoids in northwestern Argentina. Florida Entomologist 89(2): 175-182.

Natawigena H. 1993. Pestisida dan kegunaannya. Penerbit Armico. Bandung.

Ozdemir I, R Kusiyev, I Erper dan C Tuncer. 2019. Efficacy of entomopathogenic fungi Beauveria bassiana and Metarhizium anisopliae against Thaumetopoea pityocampa Shiff. (Lepidoptera: Thaumatopoeidae). Archives of phytopathology and plant protection 52: 470-480.

Prasanna B, E Joseph, Huesing, R Eddy dan $\checkmark$ Peschke. 2018. Fall Armyworm in Africa: A Guide for Integrated Pest Management, First Edition. Mexico: CDMX CIMMYT.

Rosmiati A, C Hidayat, E Firmansyah dan Y Setiati. 2018. Potensi Beuveria 
bassiana sebagai agens hayati Spodoptera litura Fabr. pada tanaman kedelai. Jurnal Agrikultura 29(1): 4347.

Sharanabasappa, C Kalleswaraswamy, M Maruti dan H Pavithra. 2018. Biology of Invasive Fall Army Worm Spodoptera frugiperda (J.E. Smith) (Lepidoptera: Noctuidae) On Maize. Indian Journal of Entomology 80(3): 540-543.

Sisay B, T Tefera, M Wakgari, G Ayalew dan E Mendesil. 2019. The efficacy of selected synthetic insecticides and botanicals against fall armyworm, Spodoptera frugiperda, in maize. Insects 10(45): 1-14.

Sudarmadji D dan S Gunawan. 1994. Patogenisitas fungi entomopatogen Beauveria bassiana terhadap Helopeltis antonii. Menara Perkebunan 62(1).

Suprapto dan Suroso. 1999. Pengaruh konsentrasi cendawan Beauveria bassiana Vuill. terhadap aspek biologi penggerek batang lada Lophobaris piperis Mars. (Curculionidae: Coleoptera). Prosi-ding Seminar Nasional Perhimpunan Entomologi Indonesia. Bogor, 16 Februari 1999.

Trisyono Y, Suputa, V Aryuwandari, M Hartaman dan Jumari. 2019.
Occurrence of heavy infestation by the fall armyworm Spodoptera frugiperda, a new alien invasive pest, in corn in Lampung Indonesia. Jurnal Perlindungan Tanaman Indonesia 23(1): 156-160.

Westbrook J, R Nagoshi, R Meagher, S Fleischer dan S Jairam. 2016. Modeling seasonal migration of fall armyworm moths. International Journal of Biometeorology 60: 255267.

Widayat W dan DJ Rayati, 1993. Pengaruh frekuensi penyemprotan jamur entomopatogenik terhadap ulat jengkal (Ectropis bhurmitra) di perkebunan teh. Simosium Patologi Serangga I. Universitas Gadjahmada: 91-103.

Wright S, M Ramos, P Avery, S Jaronski dan J Vandenberg. 2010. Comparative virulence of Beauveria bassiana isolates against lepidopteran pests of vegetable crops. Journal of invertebrate pathology 103(2010): 186-199.

Wyckhuys K dan R O'Neil. 2006. Population dynamics of Spodoptera frugiperda Smith (Lepidoptera: Noctuidae) and associated arthropod natural enemies in Honduran subsistence maize. Crop Protection 25(2006): s1180-1190. 